Publiser
Graduate Program Universitas Galuh
Master of Manajemen Studies Program

\title{
PENGARUH KOMPETENSI TERHADAP KINERJA TIM
}

\author{
Andi Hendrawan ${ }^{1}$, Aneu Yulianeu ${ }^{2}$, Kristian Cahyandi ${ }^{3}$ \\ ${ }^{1}$ Mahasiswa Program Doktor IImu Manajemen UNSOED. Dosen Akademi Maritim Indosesia \\ andihendrawan007@gmail.com \\ ${ }^{2}$ Mahasiswa Program Doktor IImu Manajemen UNSOED. Dosen STMIK DCI Tasikmalaya \\ Eamilanjusu09@gmail.com \\ ${ }^{3}$ Dosen Akademi Maritim Indonesia. \\ andykrist94@gmail.com
}

\begin{tabular}{ll}
\hline Article History : & $\begin{array}{l}\text { Abstract - The organization is currently in a pace-filled } \\
\text { environment. The speed of product development, customer }\end{array}$ \\
Recieved 22 Nopember 2017 & $\begin{array}{l}\text { response, and troubleshooting can all have a dramatic effect on } \\
\text { organizational and team performance levels. Research aims to } \\
\text { Recieved in revished form }\end{array}$ \\
26 Nopember 2017 & performance. So that will be obtained picture Dimension where \\
Acepted 5 May 2017 & the most influential in team performance. The study used a \\
Available offline 20 Oktober 2017 & sample of 40 teams selected by Random Sampling Method of \\
Available online 20 Oktober 2017 & 130 UMKM (Small and Medium Micro Enterprises) engaged in \\
Language Transcript : & various fields. The data were collected by questionnaire, \\
Indonesia & scale that has been modified by Likert scale. The results showed \\
& that: knowledge influenced to team performance (accepted), \\
Key Words : & skill influence to team performance (rejected), nature influenced \\
competence, & to team performance (accepted) and motivation influence to \\
team performance, & team performance (accepted). \\
dimension &
\end{tabular}

\section{PENDAHULUAN}

Organisasi saat ini ada di lingkungan yang penuh dengan kecepatan. Kecepatan pengembangan produk, respon terhadap pelanggan, dan pemecahan masalah semuanya dapat memiliki efek dramatis pada tingkat kinerja organisasi dan tim.

Keanekaragaman kerja dan kerja tim sangat penting bagi kemajuan organisasi global manapun dalam beberapa tahun terakhir. Penelitian menarik dan informatif di bidang tim dan kerja tim adalah bagian dari masalah yang berkaitan dengan manajemen. Ahli teori manajemen telah beralih dari menggunakan istilah 'kelompok kerja' ke 'tim' dan mereka berpendapat bahwa tim menghasilkan kinerja yang lebih baik daripada kelompok kerja (Katzenbach dan Smith, 1991).

Keberhasilan dan kinerja tim dalam suatu bidang pekerjaaan banyak ditentukan oleh tingkat kompetensi, profesionalisme dan juga komitmennya terhadap bidang yang ditekuninya. Suatu komitmen organisasi menunjukkan suatu daya dari seseorang dalam mengidentifikasikan keterlibatannya dalam suatu bagian organisasi (Modway, Porter\&Steer dalam Trianingsih, 2004). Oleh karena itu komitmen organisasional akan menimbulkan rasa ikut memiliki (sense of belonging) bagi pekerja terhadap organisasional.

Menurut Simamora (1997) kompetensi berhubungan dengan kecakapan seseorang 
dalam melaksanakan suatu pekerjaan atau produktivitas, bahwa sejauh mana seseorang dalam bekerja mencapai hasil yang memuaskan. Sedangkan menurut Winardi (2007) kompetensi seorang individu untuk terus menjalankan usaha dalam menjalani berbagai macam tugas hingga berhasil yang bisa dikerjakan oleh seseorang. Keseluruhan kompetensi individual personil pada hakikatnya dibentuk oleh sifat-sifat dan kompetensikompetensi yang harus dimiliki oleh setiap organisator harus terus memupuk "inisiatif'. Sedangkan Lowser dan Poter mendefinisikan Kompetensi sebagai karakteristik individual seperti intelegensia, manual skill, traits yangmerupakan kekuatan potensial seseorang untuk berbuat dan sifatnya stabil (As'ad, 2000). Kompetensi pada individu tersebut paling tidak ditentukan oleh tiga aspek kondisi dasar, yaitu : kondisi sensoris dan kognitif, pengetahuan tentang cara respon yang benar, dan kompetensi melaksanakan respon tersebut. Jadi kompetensi adalah what one can do dan bukanlah what he does do.

\section{KOMPETENSI}

Kompetensi sebagai kemampuan seseorang untuk menghasilkan pada tingkat yang memuaskan ditempat kerja termasuk diantaranya seseorang untuk mentrasfer dan mengaplikasikan keterampilan dan pengetahuan tersebut dalam situasi yang baru.

Pengertian kompetensi yang dikemukakan oleh para ahli, menurut Wibowo (2007) mengemukakan bahwa: Suatu kemampuan untuk malaksanakan atau melakukan suatu pekerjaan atau tugas yang dilandasi atas keterampilan dan pengetahuan serta didukung oleh sikap kerja yang dituntut oleh pekerjaan itu tersebut". Spencer and Spencer (1993), kompetensi adalah: "Karakter sikap dan perilaku, atau kemauan dan kemampuan individual yang relatif stabil ketika menghadapi situasi dan tempat kerja yang terbentuk dari sinergi antara watak, konsep diri, motivasi internal, serta kapasitas pengetahuan konseptual"

Menurut (Stump, Ratliff et al. 2010, Lester 2014), kompetensi adalah karakteristik dasar dari seseorang yang memungkinkan pegawai mengeluarkan kinerja superior dalam pekerjaannya. Berdasarkan uraian di atas makna kompetensi mengandung bagian kepribadian yang mendalam dan melekat pada seseorang dengan perilaku yang dapat diprediksi pada berbagai keadaan dan tugas pekerjaan. Prediksi siapa yang berkinerja baik dan kurang baik dapat diukur dari kriteria atau standar yang digunakan

Dalam masyarakat yang semakin kompleks ini, tidak hanya kebutuhan bagi para profesional yang telah mengembangkan kompetensi teknik dan metodologis spesifik tertentu sampai tingkat tinggi, tetapi juga untuk kompetensi transversal lainnya, seperti kompetensi partisipatif dan / atau sosial. Yang terakhir ini secara khusus menekankan kompetensi kerja sama tim (Cristina Torrelles Nada,2014)

Penelitan bertujuan untuk membuktikan pengaruh dimensi kompetensi tim terhadap kinerja tim. Sehingga akan diperoleh gambaran Dimensi mana yang paling berpengaruh dalam kinerja tim,

\section{FAKTOR-FAKTOR YANG MEMPENGARUHI KOMPETENSI}

Beberapa aspek yang terkandung dalam konsep kompetensi adalah sebagai berikut (Gordon,2000):

a) Pengetahuan (knowledge), yaitu kesadaran dalam bidang kognitif. Misalnya seorang karyawan mengetahui cara melakukan identifikasi belajar, dan bagaimana 
melakukan pembelajaran yang baik sesuai dengan kebutuhan yang ada di perusahaan.

b) Pemahaman (understanding), yaitu kedalaman kognitif, dan afektif yang dimiliki oleh individu. Misalnya, seorang karyawan dalam melaksanakan pembelajaran harus mempunyai pemahaman yang baik tentang karakteristik dan kondisi kerja secara efektif dan efisien.

c) Nilai (value), adalah suatu standar perilaku yang telah diyakini dan secara psikologis telah menyatu dalam diri seseorang. Misalnya, standar perilaku para karyawan dalam melaksanakan tugas (kejujuran, keterbukaan, demokratis, dan lain-lain).

d) Kemampuan (skill), adalah sesuatu yang dimiliki oleh individu untuk melaksanakan tugas atau pekerjaan yang dibebankan kepada karyawan.

e) Sikap (attitude), yaitu perasaan (senang-tidak senang, suka-tidak suka) atau reaksi terhadap suatu rangsangan yang datang dari luar. Misalnya reaksi terhadap krisis ekonomi, perasaan terhadap kenaikan gaji.

f) Minat (interest), adalah kecenderungan seseorang untuk melakukan suatu perbuatan. Misalnya melakukan suatu aktivitas kerja.

Komptensi team tidak jauh dari komptensi individu yang terdiri dari beberapa dimensi, Leggat (2007) dimensi komptensi tim natara lain: Pengetahuan, Skill, sifat dan motivasi.

\section{ASPEK-ASPEK YANG TERKANDUNG DALAM KOMPETENSI}

Nurick \& Thamhain (1999) dalam tulisannya menerangkan, ada empat variabel yang spesifik yang akan mempengaruhi kinerja sebuah tim proyek dapat berprestasi, yaitu variabel kepemimpinan (leadershipvariables), variabel yang berhubungan dengan tugas atau pekerjaan (task-related variables), yang berhubungan dengan anggotanya (people-related), dan variabel organisasi atau perusahaan (organizational variables). Bubshait \& Farooq (2003) menyebutkan tentang faktor-faktor pengaruh kualitas dan efektivitas suatu tim proyek dibagi menjadi empat bagian, yaitu : Variabel yang berhubungan dengan gaya kepemimpinan, Variabel yang berhubungan dengan tugas, Variabel yang berhubungan dengan anggota tim, Variabel yang berhubungan dengan organisasi atau perusahaan.

Tim kerja (team work) di dalam perusahaan dapat didefinisikan sebagai sekumpulan orang yang berinteraksi satu sama lain, secara psikologi memiliki rasa keterkaitan satu sama lain dan bekerja bersama sebagai kelompok (Schein 1988 dalam Senior dan Swailes 2004). Tim kerja juga dapat didefinisikan sebagai karyawan yang berasal dari beberapa divisi kerja yang berbeda, seperti divisi keuangan, marketing, produksi atau divisi ahli lainnya dari suatu perusahaan (Sisaye 2005). Tim kerja yang efektif memiliki beberapa karakteristik, diantaranya bekerja secara bersama untuk mencapai tujuan perusahaan, memiliki ketergantungan dan kepercayaan satu sama lain dan mengambil keputusan berdasarkan kesepakatan bersama (Mullins 2002 dalam Senior dan Swailes 2004). Kinerja tim (team performance) merupakan faktor penentu utama dan seringkali digunakan sebagai indikator keberhasilan suatu perusahaan (Stashevsky dan Koslowsky 
2006). Agar suatu kelompok kerja dapat berjalan dengan efektif, setiap anggota kelompok sebaiknya memiliki tugas maupun peranan masing-masing. Peran kerja (task roles) merupakan upaya yang dilakukan oleh masing-masing anggota kelompok sehingga seluruh aktivitas dapat dikoordinasikan dengan baik. Selain itu, melalui peran kerja yang jelas akan diperoleh ide-ide baru serta dapat menyelesaikan masalah dengan baik (Chong 2007).
Pada penelian Torrelles (2011) memahami kompetensi kerja sama tim sebagai "seperangkat pengetahuan, keterampilan dan sikap yang dibutuhkan untuk bekerja dengan orang lain dalam menjalankan tugas dan mencapai tujuan bersama, berbagi informasi, mendistribusikan tugas, mengambil tanggung jawab, menyelesaikan masalah dan berkontribusi terhadap perbaikan dan pengembangan kolektif. "

Tabel 1. Desain alat pengukuran penelitian

\begin{tabular}{clll}
\hline \multicolumn{1}{c}{ Variabel } & \multicolumn{1}{c}{ Dimensi } & Skala & Referensi \\
\hline \multirow{3}{*}{ komptensi } & Pengetahuan & & \\
& Skill & Likert & legat (2007) \\
& sifat & & \\
& motivasi & & \\
& Melaksanakan tugas & & \\
& Pengambilan & & \\
Kinerja Tim & Keputusan & Cikert & Cristina Torrelles Nada (2007) \\
& Pemantauan kinerja & & \\
& Pemecahan masalah & & \\
& kolaboratif & & \\
\hline
\end{tabular}

\section{METODOLOGI}

Jumlah sampel sebanyak 40 tim dipilih dengan Metode Random Sampling dari 130 UMKM (Usaha Mikro Kecil dan menengah) di wilayah Kabupaten Cilacap. yang bergerak di berbagai bidang. Pengumpulan data dilakukan dengan kuesioner, observasi, dan wawancara. Instrumen penelitian menggunakan skala Likert yang telah dimodifikasi dengan skala 1-7. Teknik analisis menggunakan analisa regeresi dan korelasi program komputer SPSS 15.

Uji validitas instrumen dilakukan dengan menghitung nilai korelasi product moment dari tiap-tiap butir pernyataan dan didapat hasil bahwa semua butir pertanyaan memiliki nilai di atas 0,3 yang berarti semua butir pernyataan dalam kuisioner adalah valid. Uji reliabilitas dilakukan dengan menghitung nilai koefisien alpha dari semua variabel dan diperoleh hasil semua variabel menunjukkan nilai di atas 0,60 yang berarti semua variabel adalah reliabel. Adapun hipotesis dari penelitian ini adalah: 1) Pengetahuan berpengaruh terhadap kinerja tim; 2) Skil berpengaruh terhadap kinerja tim: 3) Sifat berpengaruh terhadap kinerja tim; 4) Motivasi berpengaruh terhadap kinerja tim; 5) Kompetensi berpengaruh terhadap kinerja tim. 


\section{HASIL DAN PEMBAHASAN}

Analisa regresi pengaruh dimensi kompetensi (pengetahuan, skill, sifat dan motivasi) diperlihatkan pada Tabel 2. Berdasarkan hasil pada Tabel 2, maka pengaruh pengetahuan terhadap kinerja tim signifikan, pengaruh sifat terhadap kinerja tim signifikan dan pengaruh motivasi terhadap kinerja tim siginifikan. Berarti hipotesis :
1) Pengetahuan berpengaruh terhadap kinerja tim (diterima)

2) Skil berpengaruh terhadap kinerja tim (ditolak)

3) Sifat berpengaruh terhadap kinerja tim (diterima)

4) Motivasi berpengaruh terhadap kinerja tim (diterima).

Tabel 2. Hasil Analisa Regresi Antara Dimensi Kompetensi Dengan Kinerja Tim

\begin{tabular}{llrrrrr}
\hline \multirow{2}{*}{ Model } & \multicolumn{2}{c}{$\begin{array}{c}\text { Unstandardized } \\
\text { Coefficients }\end{array}$} & $\begin{array}{c}\text { Standardized } \\
\text { Coefficients }\end{array}$ & \multirow{2}{*}{ t } & \multirow{2}{*}{ Sig. } \\
\cline { 2 - 4 } & \multicolumn{1}{c}{ B } & \multicolumn{1}{c}{ Std. Error } & \multicolumn{1}{c}{ Beta } & & \\
\hline \multirow{2}{*}{1} & (Constant) & 8.838 & 1.090 & & 8.106 & .000 \\
& pengetahuan & 1.217 & .407 & .304 & 2.990 & .005 \\
& skill & .556 & .544 & .117 & 1.022 & .314 \\
& sifat & -6.071 & 1.044 & -.940 & -5.816 & .000 \\
& motivasi & 6.975 & 1.106 & 1.403 & 6.308 & .000 \\
\hline
\end{tabular}

a. Dependent Variable: kinerja tim

Tabel 3. pengaruh konpetensi terhadap kinerja tim

\begin{tabular}{rlrrrrr}
\hline & & \multicolumn{2}{c}{$\begin{array}{c}\text { Unstandardized } \\
\text { Model }\end{array}$} & \multicolumn{2}{c}{$\begin{array}{c}\text { Standardized } \\
\text { Coefficients }\end{array}$} & \multicolumn{2}{c}{ Coefficients } & t & \multirow{2}{*}{ Sig. } \\
\cline { 3 - 5 } & & \multicolumn{1}{c}{ B } & Std. Error & \multicolumn{1}{c}{ Beta } & & \\
\hline \multirow{2}{*}{1} & (Constant) & 3.850 & 1.701 & & 2.264 & .029 \\
& kompetensi & 1.268 & .118 & .867 & 10.710 & .000 \\
\hline
\end{tabular}

a. Dependent Variable: kinerja tim

Nilai beta terbesar pada variabel dimensi motivasi, hal ini berarti bahwa berdasarkan hasil riset dimensi motivasi mempunyai pengaruh paling besar dibandingan dengan dimensi yang lain. Hasil penelitian Fajar (2009) menunjukan hubungsn yang signifikan antara motivasi dengan efektifitas kerja. Mengadopsi pandangan teori berbasis sumber daya (resource-based view=RBV) untuk mengatasi masalah ini, berdasarkan RBV, kinerja merupakan fungsi dari kompetensi yang mana berkomunikasi secara positif dengan ketersediaan dan karakteristik sumber daya serta kemampuan dalam memanfaatkan sumber daya tersebut (Karimi et al., 2007; Teece et al., 1997). Salah atu kompetnsi adalah knowledge complement, pengetahuan), dan struktur (penyebaran pengetahuan) tiga jenis berdasarkan 
kerangka kerja yang diusulkan oleh Gardner dkk. (2011).

Pengetahuan merupakan pengetahuan yang dibutuhkan untuk melksanakan tugas yang diberikan, pengetahuan mengacu pada mengetahui siapa yang tahu apa yang ada dalam tim, dan penyebaran (sharing) pengetahuan merupakan pengetahuan pencocokan yang efektif dengan tugas.

Demikian studi sebelumnya pengetahuan tim telah diasumsikan bahwa konten/isi pengetahuan digunakan sebagai bahan untuk menghasilkan pengetahuan baru (Cruz, Perez, \& Ramos, 2007; Mathieu \& Schulze, 2006), sedangkan proses pengetahuan memungkinkan tim untuk menerapkan pengetahuan yang relevan, dengan demikian mengaktifkan nilai pengetahuan semacam itu dalam kinerja tim (Liang et al., 1995; Moreland \& Myaskovsky, 2000).

Analisa regresi pengaruh kompetensi dapat dilihat sebagaimana pada Tabel 3 . Berdasarkan Tabel 3 diperlihatkan bahwa komptensi berpengaruh positif terhadap kinerja tim.

Hasil penelitian (Chiung-Ju Liang,2013) terdapat hubungan antara kompetensi intidan kinerja keuangan di pusat perbelanjaan yang berdekatan dengan bandara. Kepercayaan yang baik, orientasi layanan pelanggan, prestasi, motivasi, dan inovasi, Kompetensi berpengaruh positif karena itu semakin tinggi kompetensi suatu tim maka kinerja tim tersebut juga makin baik.

\section{SIMPULAN}

Berdaarkan hasil penelitian maka dapa disimpulkan bahwa: Pengaruh pengetahuan terhadap kinerja tim signifikan, pengaruh sifat terhadap kinerja tim signifikan dan pengaruh motivasi terhadap kinerja tim siginifikan. Berarti hipotesis :Pengetahuan berpengaruh terhadap kinerja tim (diterima), Skil berpengaruh terhadap kinerja tim (ditolak), Sifat berpengaruh terhadap kinerja tim (diterima), Motivasi berpengaruh terhadap kinerja tim (diterima)Nilai beta terbesar pada variabel dimensi motivasi, hal ini berarti bahwa berdasarkan hasil riset dimensi motivasi mempunyai pengaruh paling besar dibandingan dengan dimensi yang lain.Kompetensi berpengaruh positip terhadap kinerja tim.

\section{DAFTAR PUSTAKA}

all, M. s. e. (2012). "skill comptence and gender." IES.

Bubshait \& Farooq, 2003. Team Building and Project Success, Cost Engineering, Vol 41/No 7 July 2003, 34 - 38.

Cristina Torrelles Nada .2007.Assessingteamwork competence, Psicothema 2015, Vol. 27, No. 4, 354361

Chong. 2007. Role Balance and Team Development: A Study of Team Role Characteristics Underlying High and Low Performing Teams. Institute of Behavioral and Applied Management. pp 202-217.

Chiung-Ju Liang,2013. Effect of core competence on organizational performance in an airport shopping center, Journal of Air Transport Management 31 (2013) 23e26

Cruz, N. M., Perez, V. M., \& Ramos, Y. F. (2007). Transactive memory processes that lead to better team results. Team Performance Management, 13, 192 205.

Evans,JamesR.,1994BerfikirKreatifdalamP engambilanKeputusandanManajemen .Jakarta : Bumi Aksara.

EugeneSadlerSmith., YveHampson.,IanChaston.,Ber ylBadger,2003,Managerialbehavior, entrepreneurialstyle, andsmallfirmperf ormance.JournalofSmallBusiness Management; Vol.41,No. 1,pg. 47-67.

Fillis,Ian.,AndrewMc Auley,2000,Modeling andmeasuringcreativityattheinterface. $J$ ournalofMarketing Theoryand Practice, Vol.8, No. 2,pg. 8-17.

Gardner, H., Gino, F., \& Staats, B., 2011. Dynamically integrating knowledge in teams: transforming resources into 
performance. Acad.Manag. J. 2010 (0604).

Karimi, J., Somers, T.M., \& Bhattacherjee, A., 2007. The role of information systems resources in ERP capability building and business process

outcomes. J. Manag. Inf. Syst. 24, 221-260.

Lester, S. (2014). "Professional standards, competence and capability." Higher Education, Skills and Work-Based Learning 4(1): 31-43.

Leggat, S.G. .2007. Effective healthcare teams require effective team members: defi ning teamwork competencies. BMC Health Services Research, 7, 717.

Liang, D. W., Moreland, R. L., \& Argote, L. (1995). Group versus individual training and group performance: The mediating role of transactive memory. Personality and Social Psychology Bulletin, 21, 384-393.

Mathieu, J. E., \& Schulze, W. (2006). The influence of team knowledge and formal plans on episodic team process-performance relationships. Academy of

Management Journal, 49, 605-619.

Moreland, R. L., \& Myaskovsky, L. (2000). Exploring the performance benefits of group training: Transactive memory or improved communication? Organizational Behavior \& Human Decision Processes, 82, 117-133

Nurick, A J., Thamhain, H J., Cleland D., Gareis, R., 1999. Strategic Project Management, McGraw-Hill International Editions, Chapter 19.

Prog, L. D. (2012). "Defining the Core Competencies." University of California, Berkeley.

Robbins, P. Stephen, 2003. Perilaku Organisasi: Konsep, Kontroversi, dan Aplikasi. Alih Bahasa Handayana Pujaatmika. Edisi Bahasa Indonesia. Jakarta: Prenhalindo.

R. Nikolov, E. S., E. Kovatcheva (2015). "COMPETENCE BASED FRAMEWORK FOR CURRICULUM DEVELOPMENT." PICTET: EQFbased professional ICT training. http://jurnal.unigal.ac.id/index.php/managementreview

Schermerhorn Jr John R. 2005. Management. Eight Edition. John Wiley \& Sons

Senior B, Swailes S. 2004. The Dimension of Management Team Performance: A RepertoryGrid Study. International Journal of Productivity and Performance Management; 53: 317 333.

Sisaye. 2005. Management Control Systems and Organizational Development - New Directions for Managing Work Teams. Leadership and Organization Development Journal; 26: 51 - 61.

Stashevsky, Koslowsky. 2006. Leadership Team Cohesiveness and Team Performance. International Journal of Manpower; 27(1):.63 - 74 .

Simmamora, Henry, (2004). Manajemen Sumber Daya Manusia. YKPN Yogyakarta

Stump, K. N., et al. (2010). "Theories of Social Competence from the TopDown to the Bottom-Up: A Case for Considering Foundational Human Needs." 23-37.

Szczepańska-Woszczyna, K. (2014). "Competencies, innovation and entrepreneurshipnin the theory and practice of management." Dąbrowa Górnicza 2014.

Torrelles, C. (2011). Eina d'avaluació de la competència de treball en equip [Teamwork competence assessment tool]. Tesis doctoral, Facultat de Ciències de l'Educació, Universitat de Lleida, Lleida, España.

Torrelles, C., Coiduras, J., Isus, S., Carrera, X., Paris, G., \& Cela, J. M. (2011). Competencia de trabajo en equipo: defi nición y categorización [Teamwork competence: conception and categorization]. Profesorado. Revista de currículum y formación del profesorado, 15(3) 329-344.

Teece, D.J., Pisano, G., \& Shuen, A., 1997. Dynamic capabilities and strategic management. Strateg. Manag. J. 8, 509-553

Trisnaningsih, Sri, 2001 "Pengaruh Komitmen terhadap Kepuasan Auditor :Motivasi sebagai Variabel Intervening(Studi Empiris pada Kantor 
Akuntan Publik di Jawa Tengah) "'

Jurnal Riset Akuntansi Indonesia,

Volume 6., No 2., Mei 2003 ., Jakarta:

Ikatan Akuntan Indonesia

Kompartemen Akuntan Pendidikan

University, E. (2014). "Competency

Definitions, Example Behaviors \&

Rating Scales For Performance

Management Emory University."

Emory University.

Weiss, E. S. B. a. M. R. (2011). "A Theory

of Instruction for Developing

Competence, Self-Confidence and

Persistence in Physical Education."

University of Oregon. 